\title{
The role of tonsillectomy in the Periodic Fever, Aphthous stomatitis, Pharyngitis and cervical Adenitis syndrome; a literature review
}

\author{
Jostein Førsvoll ${ }^{1,2^{*}}$ (D) and Knut Øymar ${ }^{1,2}$
}

\begin{abstract}
Background: Tonsillectomy (TE) or adenotonsillectomy (ATE) may have a beneficial effect on the clinical course in children with the Periodic Fever, Aphthous stomatitis, Pharyngitis and cervical Adenitis (PFAPA) syndrome. However, an immunological reason for this effect remains unknown. This literature review summarizes the current knowledge of the effect of TE or ATE in the PFAPA syndrome.

Methods: A search of PubMed, Medline, EMBASE and Cochrane was conducted for papers written in English dated from 1 January 1987 to 31 December 2016. The search included all studies reporting outcomes after TE or ATE from children aged 0 to 18 years with PFAPA.

Results: Two randomized controlled trials reported significantly faster resolution of febrile episodes after TE or ATE in children with PFAPA compared to controls (non-surgery groups). We identified 28 case series including 555 children with PFAPA. The diagnosis was set prospectively before surgery in 440 children and retrospectively after surgery in 115 of the children. TE or ATE had a curative effect in 509 of the 555 children with PFAPA (92\%), but few studies were of high quality.

Conclusion: TE or ATE may have a curative effect on children with PFAPA, but the evidence is of moderate quality. Further high-quality randomized controlled studies are still needed.
\end{abstract}

Keywords: PFAPA, Tonsils, Tonsillectomy, Adenotonsillectomy

\section{Background}

The Periodic Fever, Aphthous stomatitis, Pharyngitis and cervical Adenitis (PFAPA) syndrome is the most common paediatric periodic fever syndrome $[1,2]$, with a cumulative incidence of 2.2 per 10.000 children up to the age of 5 years in a Nordic population [2]. The hallmarks of the disease are short (3-5 days), regularly occurring episodes of high fever accompanied by at least one of the following major symptoms: pharyngitis, cervical adenitis and aphthous stomatitis [3-5]. The febrile episodes are accompanied by a marked inflammatory response with C-reactive protein $>100 \mathrm{mg} / \mathrm{L}$ with complete

\footnotetext{
* Correspondence: jforsvoll@gmail.com

${ }^{1}$ Department of Paediatrics, Stavanger University Hospital, PO BOX 8100,

4068 Stavanger, Norway

${ }^{2}$ Department of Clinical Science, University of Bergen, Bergen, Norway
}

normalization between the episodes [6]. Episodes of PFAPA often start during the first few years of life and often spontaneously resolve during late childhood $[2,7]$.

PFAPA has not been defined genetically, and the aetiology is unknown. A dysregulated interleukin-1 response may play a part in the aetiology of the disease $[8,9]$, and PFAPA is currently regarded as an autoinflammatory disease [10]. There is no established international consensus regarding the definition of PFAPA [11]. The clinical entity was first described by Marshall et al. in 1987 [12], and in 1989 they presented the acronym PFAPA and suggested a set of diagnostic criteria for the syndrome [13]. In 1999, Thomas et al. presented a modified set of diagnostic criteria and since then these criteria have been widely used in international studies [4]. The criteria by Marshall and Thomas are principally 
equivalent, but in addition to excluding cyclic neutropenia, the definition by Marshall et al. also systematically excludes rare hereditary periodic fever syndromes.

As early as in 1989, Abramson et al. reported that in four children with PFAPA, fever episodes ceased after tonsillectomy (TE) [14]. Since then, the outcome after TE or adenotonsillectomy (ATE) has been reported in several case series of children with PFAPA, indicating a beneficial effect of surgery on the clinical course. Based on two randomized controlled studies, a recent Cochrane review concluded that the evidence for the effect of TE in children with PFAPA is of moderate quality [15], but the case series have not been systematically described before.

There is currently no other curative treatment for children with PFAPA, and for those with bothering symptoms highly influencing daily life for the child and family, TE or ATE has become an option to consider [2, 3, 15].

This literature review summarizes the results of all studies reporting the outcome of TE or ATE in children with the PFAPA syndrome.

\section{Methods}

A systematic search of the PubMed, Medline, EMBASE and Cochrane databases was performed up to January 31th 2017 using the keywords "Marshall Syndrome", "PFAPA" and "Periodic Fever, Aphthous stomatitis, Pharyngitis and cervical Adenitis". Papers in English language published between 1 January 1987 and 31 December 2016 were checked for relevance, and the references in the relevant papers were also reviewed to identify any articles not found in the systematic search. Papers were included if they reported the outcome after TE or ATE in children aged 0 to 18 years diagnosed with PFAPA. The diagnostic criteria for the diagnosis in each study were noted; according to Marshall [12, 13], Thomas [4] or adapted criteria not clearly based on either of the two.

The outcome after TE or ATE was defined as "curative" if a cessation of febrile episodes occurred; as "partly effective" if the children experienced less frequent, shorter or less severe symptoms during subsequent febrile attacks; and as "not effective" if the disease pattern remained unchanged. The study design was reviewed, and registered if the PFAPA diagnosis was set prospectively before surgery or retrospectively after surgery had been performed. When concurrence of authorship and time, the studies were thoroughly assessed for overlap of patients included.

If a case series included $\geq 20$ patients, a follow-up of $\geq 24$ months and the diagnosis was set prior to surgery, the study was considered as high quality. If two of these criteria were present the study was considered of moderate quality, and with $\leq$ one criteria of low quality. High quality study should have included patients according to definitions by Marshall or Thomas. The review was performed according to the Additional file 1: PRISMA guidelines [16].

\section{Results}

After omitting duplicates, the search retrieved 558 manuscripts (Fig. 1). After a review of the titles, abstracts, and reference lists of the relevant manuscripts, two randomized controlled trials (RCTs) and 28 case series reporting the outcome after TE or ATE in children with PFAPA were identified. Two Cochrane studies were identified, but no other systematic reviews were found.

\section{The outcome of PFAPA after tonsillectomy with or without adenoidectomy}

The first RCT performed by Renko et al. included 26 children with PFAPA (mean age: 4.1 years) [17]. They found that tonsillectomy was curative in all 14 children randomized to the TE group, whereas six of the 12 children in the control group experienced spontaneous resolution of PFAPA episodes within 6 months after inclusion in the study $(p<0.001)$.

In the RCT by Garavello et al., 39 children with PFAPA were randomized to either ATE $(n=19)$ or expectant management $(n=20)$ groups [18]. Twelve of the children in the ATE surgery group had a prompt resolution of symptoms (63\%), whereas only one child in the control group experienced spontaneous resolution during the 18 months of follow-up $(5 \%)(p<0.001)$. The mean number of episodes recorded during the follow-up period was $0.7(1.2 ; \mathrm{SD})$ in the surgery group and 8.1 (3.9) in the control group $(\mathrm{p}<0.001)$. The episodes were further described as less severe in the surgery group.

As summarized in Table 1, the outcome after TE or ATE has been reported in 28 case series, including a total of 555 children with PFAPA. The diagnosis was set prospectively before surgery in 450 children and retrospectively after surgery in 115 of the children. Three studies were categorized as high quality, six as medium quality and 19 as low quality. Surgery was curative in 509 children (92\%), partly effective in 14 children and not effective in 32 children. Surgery was curative in 160 of 176 children (91\%) in studies with low quality and in 149 of 161 children (93\%) in studies with moderate quality. In the high quality studies, surgery was curative in 200 of 218 children (92\%). In 16 of the studies, the mean time of observation after surgery was sufficiently given, with a median time of 19 months $(11,26.5)$ (interquartile range).

Two Cochrane reviews by Burton et al. in 2010 and 2014 studied the clinical effectiveness of TE or ATE compared to nonsurgical treatment in the management of PFAPA [15, 19], both reviews based on the two randomized studies only. They concluded that TE appears to be a 
PubMed, Medline, EMBASE and Cochrane searched

from 1 January 1987 to 31 December 2016

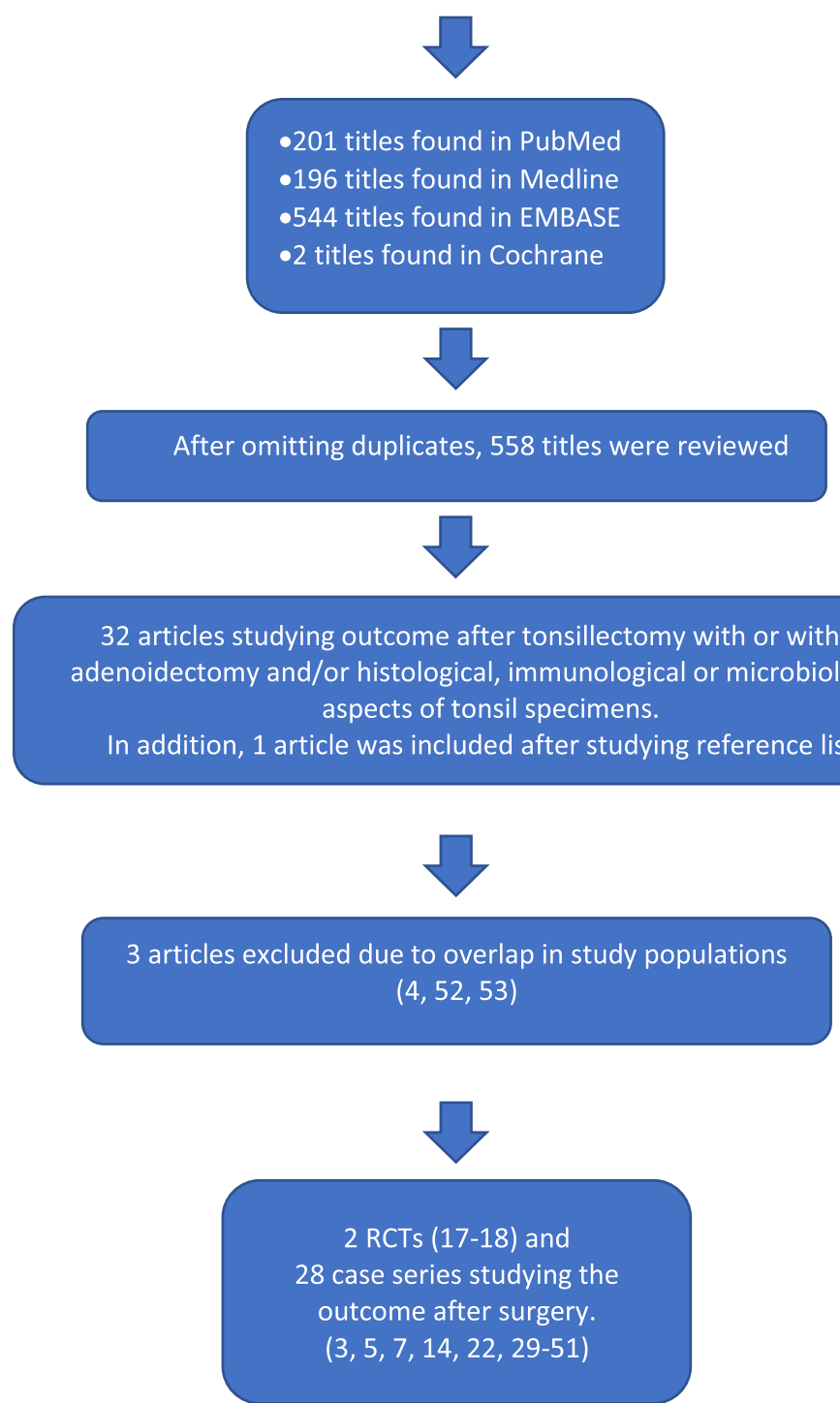

Fig. 1 Overview of the systematic literature search $[52,53]$

useful treatment option in the management of children with PFAPA syndrome, with moderate-quality evidence.

\section{Discussion}

The two RCTs performed indicate a beneficial effect of TE or ATE in children with PFAPA. The study by Renko et al. had a short time of follow-up, and has also been criticized for vague diagnostic criteria not according to Marshall or Thomas [20, 21]; the large percentage of children described as having PFAPA but with fever as their only symptom may be the reason for the speculation concerning the specificity of the PFAPA diagnosis in this study. A clear and uniform definition should be applied to compare results from studies and provide generalizability to patient fulfilling these criteria. However, in a recent publication from this study group, they showed that TE may also be effective as a treatment for children with recurring febrile episodes who do not meet the classical diagnostic criteria for PFAPA [22].

Garavello et al. did a thorough diagnostic workup of all children included in their RCT, they applied strict diagnostic criteria for PFAPA, and there was a longer time of follow-up. They performed ATE on all children who underwent surgery and showed favourable 
Table 1 Case series reporting the outcome after tonsillectomy and adenotonsillectomy in children with the PFAPA syndrome

\begin{tabular}{|c|c|c|c|c|c|c|c|c|c|c|}
\hline & $\begin{array}{l}\text { Author/year } \\
\text { (reference) }\end{array}$ & $\begin{array}{l}\text { Number of } \\
\text { children }\end{array}$ & Curative & $\begin{array}{l}\text { Partly } \\
\text { effective }\end{array}$ & $\begin{array}{l}\text { Not } \\
\text { effective }\end{array}$ & $\begin{array}{l}\text { Observation post } \\
\text { surgery } \\
\text { (months, mean) }\end{array}$ & $\begin{array}{l}\text { Adeno- } \\
\text { tonsillectomy }{ }^{\mathrm{a}}\end{array}$ & $\begin{array}{l}\text { Diagnosis set } \\
\text { prior to surgery }\end{array}$ & $\begin{array}{l}\text { Criteria for PFAPA } \\
\text { diagnosis }^{b}\end{array}$ & Quality \\
\hline 1 & $\begin{array}{l}\text { Abramson et al. } 1989 \\
\text { [14] }\end{array}$ & 4 & 4 & - & - & 15 & $3(75 \%)$ & No & Marshall & Low \\
\hline 2 & Padeh et al. 1999 [3] & 3 & 3 & - & - & Not clear & 0 & Yes & Marshall & Low \\
\hline 3 & Dahn et al. 2000 [30] & 5 & 5 & - & - & 3 & $5(100 \%)$ & No & Adapted & Low \\
\hline 4 & $\begin{array}{l}\text { Galanakis et al. } 2002 \\
\text { [31] }\end{array}$ & 15 & 15 & - & - & Not clear & 0 & No & Thomas & Low \\
\hline 5 & $\begin{array}{l}\text { Berlucchi et al. } 2003 \\
\text { [32] }\end{array}$ & 5 & 5 & - & - & 10 & $2(40 \%)$ & Yes & Adapted & Low \\
\hline 6 & Parikh et al. 2003 [33] & 2 & 0 & - & 2 & Not clear & 0 & No & Marshall & Low \\
\hline 7 & Tasher et al. 2006 [5] & 6 & 6 & - & - & 19 & 0 & Yes & Thomas & Low \\
\hline 8 & Wong et al. 2008 [34] & 9 & 8 & 1 & - & 24 & 0 & Yes & Marshall & Medium \\
\hline 9 & $\begin{array}{l}\text { Pignataro et al. } 2009 \\
\text { [35] }\end{array}$ & 9 & 5 & 4 & - & 26 & 0 & Yes & Marshall & Medium \\
\hline 10 & $\begin{array}{l}\text { Fedrer et al. } 2010 \\
\text { [36] }\end{array}$ & 11 & 11 & - & - & 18 & 0 & Yes & Thomas & Low \\
\hline 11 & $\begin{array}{l}\text { Peridis et al. } 2010 \\
\text { [37] }\end{array}$ & 9 & 8 & - & 1 & 12 & $2(22 \%)$ & Yes & Thomas & Low \\
\hline 12 & $\begin{array}{l}\text { Wurster et al. } 2011 \\
\text { [7] }\end{array}$ & 12 & 6 & 3 & 3 & Not clear & $10(83 \%)$ & Yes & Thomas & Low \\
\hline 13 & $\begin{array}{l}\text { Licameli et al. } 2012 \\
\text { [38] }^{c}\end{array}$ & 102 & 99 & - & 3 & 43 & 102 (100\%) & Yes & Marshall & High \\
\hline 14 & $\begin{array}{l}\text { Førsvoll et al. } 2013 \\
\text { [29] }\end{array}$ & 17 & 17 & - & - & Not clear & $7(41 \%)$ & Yes & Thomas & Low \\
\hline 15 & Krol et al. 2013 [39] & 18 & 18 & - & - & Not clear & 0 & Yes & Thomas & Low \\
\hline 16 & $\begin{array}{l}\text { Ter Haar et al. } 2013 \\
\text { [40] }\end{array}$ & 8 & 4 & 3 & 1 & Not clear & Not clear & Yes & Marshall & Low \\
\hline 17 & $\begin{array}{l}\text { Valenzuela et al. } 2013 \\
\text { [41] }\end{array}$ & 9 & 9 & - & - & 10 & 0 & Yes & Thomas & Low \\
\hline 18 & $\begin{array}{l}\text { Kubota et al. } 2014 \\
\text { [42] }\end{array}$ & 5 & 4 & - & 1 & Not clear & 0 & Yes & Thomas & Low \\
\hline 19 & Vigo et al. 2014 [43] & 41 & 27 & - & 14 & 69 & 0 & Yes & Marshall & High \\
\hline 20 & $\begin{array}{l}\text { Dytrych et al. } 2015 \\
\text { [44] }\end{array}$ & 10 & 10 & - & - & 19 & 0 & Yes & Thomas & Low \\
\hline 21 & $\begin{array}{l}\text { Førsvoll et al. } 2015 \\
\text { [45] }\end{array}$ & 4 & 4 & - & - & 27 & $1(25 \%)$ & Yes & Thomas & Medium \\
\hline 22 & $\begin{array}{l}\text { Lantto et al. } 2015 \\
\text { [46] }^{d}\end{array}$ & 31 & 31 & - & - & 6 & $11(35 \%)$ & No & Adapted & Low \\
\hline 23 & Perko et al. 2015 [47] & 28 & 26 & 2 & - & Not clear & 0 & Yes & Thomas & Medium \\
\hline 24 & Batu et al. $2016[48]^{c}$ & 53 & 50 & - & 3 & Not clear & 0 & Yes & Thomas & Medium \\
\hline 25 & $\begin{array}{l}\text { Dusser et al. } 2016 \\
\text { [49] }\end{array}$ & 4 & 3 & - & 1 & Not clear & Not clear & Yes & Thomas & Low \\
\hline 26 & $\begin{array}{l}\text { Erdogan et al. } 2016 \\
\text { [50] }\end{array}$ & 75 & 74 & 1 & - & 24 & Not clear & Yes & Thomas & High \\
\hline 27 & $\begin{array}{l}\text { Lantto et al. } 2016 \\
{[22]^{d}}\end{array}$ & 58 & 56 & - & 2 & 107 & 0 & No & Thomas & Medium \\
\hline \multirow[t]{2}{*}{28} & $\begin{array}{l}\text { Rigante et al. } 2016 \\
\text { [51] }\end{array}$ & 2 & 1 & - & 1 & Not clear & 0 & Yes & Thomas & Low \\
\hline & Total & 555 & 509 & 14 & 32 & - & 143 (26\%) & - & & \\
\hline
\end{tabular}

PFAPA Periodic Fever, Aphthous stomatitis, Pharyngitis and cervical Adenitis

a:Adenotonsillectomy performed instead of tonsillectomy alone

b:PFAPA diagnosis was set according to criteria by Marshall [13], Thomas [4] or adapted criteria not clearly based on either of the two

${ }^{c}$ and ${ }^{\mathrm{d}}$ :Possible overlap between study populations 
outcomes for these children compared with the control group. Therefore, this study may serve as the best evidence for TE or ATE in children with PFAPA.

Case series have important limitations and provide the lowest level of evidence. A beneficial outcome after TE or ATE in 523 of 555 children is impressive. However, only three studies were considered by us as high quality. In one of these studies, TE was curative in only $66 \%$ of patients, but in $92 \%$ of patients in all the high quality studies together. Moreover, subgroups of patients may have been selected for the operations, and publication bias may be another important limitation for case series. Several of the case series lack information regarding follow-up or have a brief period of follow-up. Therefore, a firm conclusion on the effect of TE or ATE cannot be drawn based on these studies.

It is not clear if ATE is more effective than TE alone. In the highest-quality study included in this review, the RCT by Garavello et al., ATE was performed in all children. Further studies are needed to confirm these findings and bring clarity to this issue.

Tonsillectomy for PFAPA has also been described in adult patients with PFAPA, but the results are not included in this review. The data are limited, but the procedure seems to be less effective for adults than for children [23-26].

Taken together, a high rate of success of TE or ATE has been shown in two RCTs, of which one with high quality, and in case series with high and moderate quality. In our opinion the current literature therefore supports TE or ATE as a treatment option for children with PFAPA, but with a moderate level of evidence. However, the disease is benign with a high likelihood of spontaneous resolution during childhood $[2,5,7]$. In one study of 59 children with PFAPA, the mean duration of symptoms before resolution was 6.3 years [7], whereas in one study of 46 children, the median age of resolution differed by only 10 months between those who were operated or not [2]. The indication for surgery must therefore be evaluated separately in each child based on the burden of the disease, the impact of recurrent febrile episodes on the family, and signs of impending resolution, such as less-severe and shorter febrile episodes and longer afebrile intervals $[2,5]$. The decision must be taken by physicians and parents together based on the degree of symptoms and the best possible knowledge of different outcomes.

Several studies have indicated that a dysregulated immune system may play a part in the aetiology of PFAPA [8, 9, 27-29]. In 2011, Stojanov et al. proposed a model for PFAPA where a microbial trigger initiates a cascade leading to the febrile attacks. They suggested that an immunologically immature host or a host with an inherited or acquired immune abnormality plays a permissive role [8]. However, the observation that removal of the tonsils, which serve as a minor part of the secondary immune system, may be curative for a disease that is possibly caused by a dysregulated immune system remains puzzling.

\section{Conclusion}

In conclusion, two RCTs and several case series indicate that TE or ATE has a beneficial effect on the course of PFAPA, but the evidence is of moderate quality. Surgery must be weighed against the chance of spontaneous recovery. More RCTs on the effect of TE with strict diagnostic criteria for PFAPA are needed.

\section{Additional file}

Additional file 1: PRISMA guidelines checklist (DOC $63 \mathrm{~kb}$ )

\section{Abbreviations}

ATE: Adenotonsillectomy; PFAPA: Periodic fever, aphthous stomatitis, pharyngitis and cervical adenitis; RCT: Randomized controlled trial;

TE: Tonsillectomy

\section{Acknowledgements}

Not applicable

\section{Funding}

The authors received no funding for this work.

Availability of data and materials

Not applicable.

\section{Authors' contributions}

The authors have contributed equally to the manuscript. $K \varnothing$ wrote the first draft of the manuscript. JF performed the literature search. Both authors revised the manuscript and prepared it for publication. Both authors read and approved the final manuscript.

Ethics approval and consent to participate

Not applicable.

Consent for publication

Not applicable.

Competing interests

The authors have no competing interests.

\section{Publisher's Note}

Springer Nature remains neutral with regard to jurisdictional claims in published maps and institutional affiliations.

Received: 20 June 2017 Accepted: 20 December 2017

Published online: 22 February 2018

\section{References}

1. Masters SL, Simon A, Aksentijevich I, Kastner DL. Horror autoinflammaticus: the molecular pathophysiology of autoinflammatory disease. Annu Rev Immunol. 2009:27:621-68.

2. Forsvoll J, Kristoffersen EK, Oymar K. Incidence, clinical characteristics and outcome in Norwegian children with periodic fever, aphthous stomatitis, pharyngitis and cervical adenitis syndrome; a population-based study. Acta Paediatr. 2013;102:187-92.

3. Padeh S, Brezniak N, Zemer D, Pras E, Livneh A, Langevitz P, et al. Periodic fever, aphthous stomatitis, pharyngitis, and adenopathy syndrome: clinical characteristics and outcome. J Pediatr. 1999;135:98-101. 
4. Thomas KT, Feder HM Jr, Lawton AR, Edwards KM. Periodic fever syndrome in children. J Pediatr. 1999;135:15-21.

5. Tasher D, Somekh E, Dalal I. PFAPA syndrome: new clinical aspects disclosed. Arch Dis Child. 2006:91:981-4

6. Forsvoll JA, Oymar K. C-reactive protein in the periodic fever, aphthous stomatitis, pharyngitis and cervical adenitis (PFAPA) syndrome. Acta Paediatr. 2007;96:1670-3.

7. Wurster VM, Carlucci JG, Feder HM Jr, Edwards KM. Long-term follow-up of children with periodic fever, aphthous stomatitis, pharyngitis, and cervical adenitis syndrome. J Pediatr. 2011;159:958-64.

8. Stojanov S, Lapidus S, Chitkara P, Feder H, Salazar JC, Fleisher TA, et al. Periodic fever, aphthous stomatitis, pharyngitis, and adenitis (PFAPA) is a disorder of innate immunity and Th1 activation responsive to IL-1 blockade. Proc Natl Acad Sci U S A. 2011;108:7148-53.

9. Kolly L, Busso N, von Scheven-Gete A, Bagnoud N, Moix I, Holzinger D, et al, Periodic fever, aphthous stomatitis, pharyngitis, cervical adenitis syndrome is linked to dysregulated monocyte IL-1beta production. J Allergy Clin Immunol. 2013;131:1635-43.

10. Wekell P, Karlsson A, Berg S, Fasth A. Review of autoinflammatory diseases, with a special focus on periodic fever, aphthous stomatitis, pharyngitis and cervical adenitis syndrome. Acta Paediatr. 2016;105:1140-51.

11. Hofer M, Pillet P, Cochard MM, Berg S, Krol P, Kone-Paut I, et al. International periodic fever, aphthous stomatitis, pharyngitis, cervical adenitis syndrome cohort: description of distinct phenotypes in 301 patients. Rheumatology (Oxford). 2014;53:1125-9.

12. Marshall GS, Edwards KM, Butler J, Lawton AR. Syndrome of periodic fever, pharyngitis, and aphthous stomatitis. J Pediatr. 1987;1 10:43-6.

13. Marshall GS, Edwards KM, Lawton AR. PFAPA syndrome. Pediatr Infect Dis J. 1989:8:658-9.

14. Abramson JS, Givner LB, Thompson JN. Possible role of tonsillectomy and adenoidectomy in children with recurrent fever and tonsillopharyngitis. Pediatr Infect Dis J. 1989:8:119-20.

15. Burton MJ, Pollard AJ, Ramsden JD, Chong LY, Venekamp RP. Tonsillectomy for periodic fever, aphthous stomatitis, pharyngitis and cervical adenitis syndrome (PFAPA). Cochrane Database Syst Rev. 2014;9:CD008669.

16. Liberati A, Altman DG, Tetzlaff J, Mulrow C, Gøtzsche PC, loannidis JP, et al. The PRISMA statement for reporting systematic reviews and meta-analyses of studies that evaluate health care interventions: explanation and elaboration. PLoS Med. 2009; https://doi.org/10.1371/journal.pmed.1000100.

17. Renko M, Salo E, Putto-Laurila A, Putto-Laurila A, Saxen H, Mattila PS, et al. A randomized, controlled trial of tonsillectomy in periodic fever, aphthous stomatitis, pharyngitis, and adenitis syndrome. J Pediatr. 2007;151:289-92.

18. Garavello W, Romagnoli M, Gaini RM, Garavello W, Romagnoli M, Gaini RM Effectiveness of adenotonsillectomy in PFAPA syndrome: a randomized study. J Pediatr. 2009;155:250-3.

19. Burton MJ, Pollard AJ, Ramsden JD. Tonsillectomy for periodic fever, aphthous stomatitis, pharyngitis and cervical adenitis syndrome (PFAPA) Cochrane Database Syst Rev. 2010;9:CD008669.

20. Spalding SJ, Hashkes PJ. The role of tonsillectomy in management of periodic fever, aphthous stomatitis, pharyngitis, and adenopathy: unanswered questions. J Pediatr. 2008;152:742-3.

21. Hofer MF. Cured by tonsillectomy: was it really a PFAPA syndrome? J Pediatr. 2008;153:298.

22. Lantto U, Koivunen P, Tapiainen T, Renko M. Long-term outcome of classic and incomplete PFAPA (periodic fever, Aphthous Stomatitis, Pharyngitis, and adenitis) syndrome after tonsillectomy. J Pediatr. 2016;179:172-7.

23. Padeh S, Stoffman N, Berkun Y, Padeh S, Stoffman N, Berkun Y. Periodic fever accompanied by aphthous stomatitis, pharyngitis and cervical adenitis syndrome (PFAPA syndrome) in adults. Isr Med Assoc J. 2008;10:358-60.

24. Colotto M, Maranghi M, Durante C, Rossetti M, Renzi A, Anatra MG. PFAPA syndrome in a young adult with a history of tonsillectomy. Intern Med. 2011:50:223-5.

25. Cantarini L, Vitale A, Bartolomei B, Galeazzi M, Rigante D. Diagnosis of PFAPA syndrome applied to a cohort of 17 adults with unexplained recurrent fevers. Clin Exp Rheumatol. 2012;30:269-71

26. Cantarini L, Vitale A, Galeazzi M, Frediani B. A case of resistant adult-onset periodic fever, aphthous stomatitis, pharyngitis and cervical adenitis (PFAPA) syndrome responsive to anakinra. Clin Exp Rheumatol. 2012;30:593.

27. Stojanov S, Hoffmann F, Kery A, Renner ED, Hartl D, Lohse P, et al. Cytokine profile in PFAPA syndrome suggests continuous inflammation and reduced anti-inflammatory response. Eur Cytokine Netw. 2006;17:90-7.
28. Brown KL, Wekell P, Osla V, Sundqvist M, Savman K, Fasth A, et al. Profile of blood cells and inflammatory mediators in periodic fever, aphthous stomatitis, pharyngitis and adenitis (PFAPA) syndrome. BMC Pediatr. 2010;10:65.

29. Forsvoll J, Kristoffersen EK, Oymar K. Elevated levels of CXCL10 in the periodic fever, Aphthous stomatitis, Pharyngitis and cervical adenitis syndrome (PFAPA) during and between febrile episodes; an indication of a persistent activation of the innate immune system. Pediatr Rheumatol Online J. 2013;11:38.

30. Dahn KA, Glode MP, Chan KH. Periodic fever and pharyngitis in young children: a new disease for the otolaryngologist? Arch Otolaryngol Head Neck Surg. 2000;126:1146-9.

31. Galanakis E, Papadakis CE, Giannoussi E, Karatzanis AD, Bitsori M, Helidonis ES. PFAPA syndrome in children evaluated for tonsillectomy. Arch Dis Child. 2002;86:434-5.

32. Berlucchi M, Meini A, Plebani A, Bonvini MG, Lombardi D, Nicolai P. Update on treatment of Marshall's syndrome (PFAPA syndrome): report of five cases with review of the literature. Ann Otol Rhinol Laryngol. 2003;112:365-9.

33. Parikh SR, Reiter ER, Kenna MA, Roberson D. Utility of tonsillectomy in 2 patients with the syndrome of periodic fever, aphthous stomatitis, pharyngitis, and cervical adenitis. Arch Otolaryngol Head Neck Surg. 2003; 129:670-3.

34. Wong KK, Finlay JC, Moxham JP, Wong KK, Finlay JC, Moxham JP. Role of tonsillectomy in PFAPA syndrome. Arch Otolaryngol Head Neck Surg. 2008; 134:16-9.

35. Pignataro L, Torretta S, Pietrogrande MC, Dellepiane RM, Pavesi P, Bossi A, et al. Outcome of tonsillectomy in selected patients with PFAPA syndrome. Arch Otolaryngol Head Neck Surg. 2009;135:548-53.

36. Feder HM, Salazar JC. A clinical review of 105 patients with PFAPA (a periodic fever syndrome). Acta Paediatr. 2010;99:178-84.

37. Peridis S, Koudoumnakis E, Theodoridis A, Stefanaki K, Helmis G, Houlakis M. Surgical outcomes and histology findings after tonsillectomy in children with periodic fever, aphthous stomatitis, pharyngitis, and cervical adenitis syndrome. Am J Otolaryngol. 2010;31:472-5

38. Licameli G, Lawton M, Kenna M, Dedeoglu F. Long-term surgical outcomes of adenotonsillectomy for PFAPA syndrome. Arch Otolaryngol Head Neck Surg. 2012;138:902-6.

39. Krol P, Bohm M, Sula V, Dytrych P, Katra R, Nemcova D, et al. PFAPA syndrome: clinical characteristics and treatment outcomes in a large singlecentre cohort. Clin Exp Rheumatol. 2013;31:980-7.

40. Ter Haar N, Lachmann H, Ozen S, Woo P, Uziel Y, Modesto C, et al. Treatment of autoinflammatory diseases: results from the Eurofever registry and a literature review. Ann Rheum Dis. 2013;72:678-85.

41. Valenzuela PM, Araya A, Perez Cl, Maul X, Serrano C, Beltran C, et al. Profile of inflammatory mediators in tonsils of patients with periodic fever, aphthous stomatitis, pharyngitis, and cervical adenitis (PFAPA) syndrome. Clin Rheumatol. 2013;32:1743-9.

42. Kubota K, Ohnishi H, Teramoto T, Kawamoto N, Kasahara K, Ohara O, et al. Clinical and genetic characterization of Japanese sporadic cases of periodic fever, aphthous stomatitis, pharyngitis and adenitis syndrome from a single medical center in Japan. J Clin Immunol. 2014;34:584-93.

43. Vigo G, Martini G, Zoppi S, Vittadello F, Zulian F. Tonsillectomy efficacy in children with PFAPA syndrome is comparable to the standard medical treatment: a long-term observational study. Clin Exp Rheumatol. 2014; 32(Suppl 84):156-9.

44. Dytrych P, Krol P, Kotrova M, Kuzilkova D, Hubacek P, Krol L, et al. Polyclonal, newly derived T cells with low expression of inhibitory molecule PD-1 in tonsils define the phenotype of lymphocytes in children with periodic fever, Aphtous Stomatitis, Pharyngitis and adenitis (PFAPA) syndrome. Mol Immunol. 2015:65:139-47.

45. Forsvoll J, Janssen EA, Moller I, Wathne N, Skaland I, Klos J, et al. Reduced number of CD8+ cells in tonsillar germinal centers in children with the periodic fever, aphthous stomatitis, pharyngitis and cervical adenitis syndrome. Scand J Immunol. 2015;82:76-83

46. Lantto $U$, Koivunen $P$, Tapiainen $T$, Glumoff $V$, Hirvikoski $P$, Uhari $M$, et al. Microbes of the tonsils in PFAPA (periodic fever, Aphtous stomatitis, Pharyngitis and adenitis) syndrome - a possible trigger of febrile episodes. APMIS. 2015;123:523-9.

47. Perko D, Debeljak M, Toplak N, Avcin T. Clinical features and genetic background of the periodic fever syndrome with aphthous stomatitis, pharyngitis, and adenitis: a single center longitudinal study of 81 patients. Mediat Inflamm. 2015; https://doi.org/10.1155/2015/293417. 
48. Batu ED, Kara Eroglu F, Tsoukas P, Hausmann JS, Bilginer Y, Kenna MA, et al. Periodic fever, Aphthosis, Pharyngitis, and adenitis syndrome: analysis of patients from two geographic areas. Arthritis Care Res (Hoboken). 2016;68: 1859-65.

49. Dusser P, Hentgen V, Neven B, Kone-Paut I. Is colchicine an effective treatment in periodic fever, aphtous stomatitis, pharyngitis, cervical adenitis (PFAPA) syndrome? Joint Bone Spine. 2016;83:406-11.

50. Erdogan F, Kulak K, Ozturk O, Ipek IO, Ceran O, Seven H. Surgery vs medical treatment in the management of PFAPA syndrome: a comparative trial. Paediatr Int Child Health. 2016;36:270-4.

51. Rigante D, Vitale A, Natale MF, Lopalco G, Andreozzi L, Frediani B, et al. A comprehensive comparison between pediatric and adult patients with periodic fever, aphthous stomatitis, pharyngitis, and cervical adenopathy (PFAPA) syndrome. Clin Rheumatol. 2017;36:463-8.

52. Tejesvi MV, Uhari M, Tapiainen T, Pirttila AM, Suokas M, Lantto U, et al. Tonsillar microbiota in children with PFAPA (periodic fever, aphthous stomatitis, pharyngitis, and adenitis) syndrome. Eur J Clin Microbiol Infect Dis. 2016; https://doi.org/10.1007/s10096-016-2623-y.

53. Licameli G, Jeffrey J, Luz J, Jones D, Kenna M, Greg L, et al. Effect of adenotonsillectomy in PFAPA syndrome. Arch Otolaryngol Head Neck Surg. 2008;134:136-40.

\section{Submit your next manuscript to BioMed Central and we will help you at every step:}

- We accept pre-submission inquiries

- Our selector tool helps you to find the most relevant journal

- We provide round the clock customer support

- Convenient online submission

- Thorough peer review

- Inclusion in PubMed and all major indexing services

- Maximum visibility for your research

Submit your manuscript at www.biomedcentral.com/submit 